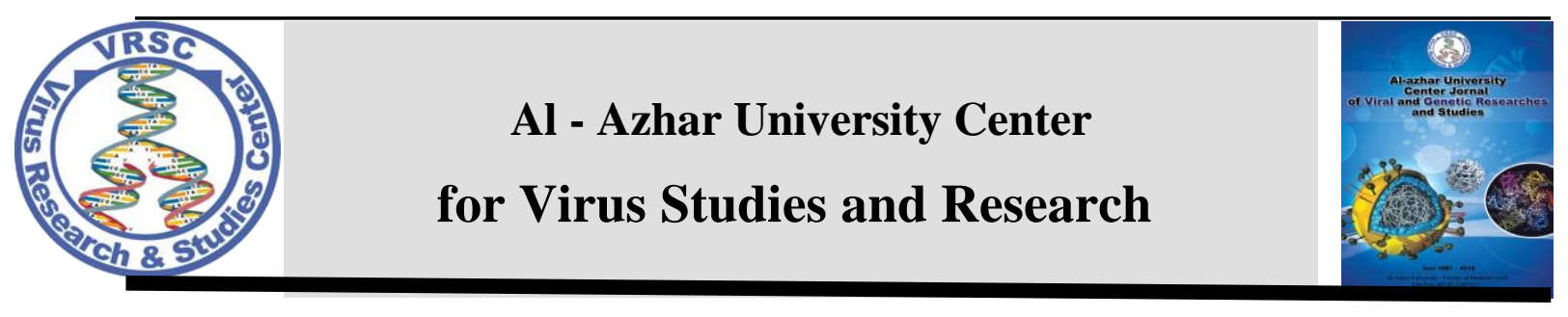

\title{
ASSESSMENT THE IMPACT OF THE USE OF POLYMER NPS IN TREATMENT OF EXPERIMENTAL MURINE TOXOPLASMOSIS
}

\author{
Noha F. Zahran', Ibrahim R. Aly², Doaa A. Amer ${ }^{1}$ and Mai A. Hegazi ${ }^{1}$
}

noha.zahran1984@gmail.com, ibrahimshalash@yahoo.com, doaaamer85@yahoo.com and maihegazi@yahoo.com.

1. Parasitology Department. Faculty of Medicine for Girls, Al-Azhar University

2.Parasitology Department- Theodor Bilharz Research Institute.

\section{Abstract}

Toxoplasma gondii (T. gondii) is an obligate intracellular protozoan parasite of adverse effect on fetus and immunocompromised host. The potential therapeutic effect of spiramycinloaded poly lactic-co-glycolic acid (PLGA) nanoparticles (NPs) was evaluated for treatment of acute murine Toxoplasmosis. Fifty Swiss albino mice were grouped into five (ten each). Groups 1 and 2 were kept as untreated controls, negative and positive, respectively. Tested mice were subcutaneously injected by the virulent $\mathrm{RH}$ strain of $T$. gondii $\left(\mathbf{1 0}^{3}\right.$ tachyzoite/ mouse) and simultaneously treated by spirmycin alone (group 3), PLGA alone (group 4) and spiramycin loaded PLGA (group 5). The treatment lasted for 7 consecutive days. Spirmycin was administered in doses of $200 \mathrm{mg} / \mathrm{kg} /$ body weight once daily while $200 \mu \mathrm{g} / \mathrm{kg} / \mathrm{day}$ was the dose for PLGA (groups 4 and 5). On the seventh day post infection the animals were sacrificed for evaluation. The toxicity induced by the treatment was estimated by measuring reduced glutathione (GSH) and malondialdehyde (MDA) in different tissues. The immune response associated with the treatment was estimated by measuring interferon gamma (IFN- $\gamma$ ), tumor necrosis factor alpha (TNF- $\alpha$ ) and IgM in serum samples. In comparison to the infected groups (non-treated, spiramycin treated and PLGANPs treated) spiramycin loaded PLGANPs showed a significant reduction in the number of tachyzoites $(P<0.05)$ in peritoneal fluid, liver and spleen, achieved the significant least toxicity of the tissues (liver, kidney and 
intestine) as reflected by mean levels of GSH and MDA levels. In spite of significant raising of the mean level of IFN- $\gamma(\mathrm{P}<\mathbf{0 . 0 5})$ in group 5, however the mean levels of IgM, TNF- $\alpha$ were significantly reduced $(P<0.05)$. This study supports the role of PLGANPs in the optimal performance of spiramycin and confirms its efficiency in achieving treatment of murine toxoplasmosis.

\section{Keywords}

Toxoplasmosis, Spiramycin, PLGANPS, GSH, MDA.

\section{INTRODUCTION}

The apicomplexan parasite $T$. gondii is an obligate intracellular coccidian parasite of humans and other mammals. In spite of almost asymptomatic infection the parasite has an adverse sequel on fetus and immunocompromised patients [1]. The active, rapidly replicating and disseminating tachyzoite form that causes pathological effect is the main target in treatment [1]. However, an ideal drug for treatment would show parasiticidal properties against the different parasitic stages with high efficacy and low toxicity. The proper treatment regimen is subjected to many disputes with no approved options for treatment [2].

Spiramycin is a potent bacteriostatic, established macrolide that has long ago been shown to be effective in murine Toxoplasma infection [3]. It has minimal fetal toxicity and it prevents the spreading of the parasite to the fetus through the placenta [4]. The pharmacokinetic data for spiramycin include evidence of its high intracellular concentration, tissue penetration and postantibiotic effect. These features allow its use in the treatment of a range of infections [5]. The bioavailability of spiramycin as any drug, is affected by many factors such as membrane permeability and solubility [6]. The absorption of spiramycin is incomplete with an oral bioavailability of $33 \%$ to $39 \%$ (range, $10 \%$ to $69 \%$ ). The rate of absorption is slower compared to erythromycin and is thought to be due to the high negative log of the acid dissociation constant (pKa 7.9) of spiramycin, suggesting a high degree of ionization in the acidic stomach [7]. The greatest disadvantage of the mechanism of action is the developing resistance which occurs quite easily because the bacteria only have to modify their ribosomal enzyme system. Moreover, macrolides carry the problem of crossresistance: If one bacterium becomes resistant to one macrolide, it is resistant to every other macrolide, too. Hence, spiramycin like mentioned before an outdated medication [8]. Although spiramycin mechanism of action is not fully defined, it is believed to act as an inhibitor of protein synthesis by binding to the 50S subunit of bacterial ribosomes. Like other macrolides, it is bacteriostatic [9].

Nanoparticles have been to date extensively used for various applications including better delivery of molecules or drugs $[10,11,13,14,15]$. At least in theory, they are a tool to optimize pharmacological data such as drug release, tissue specificity and even cell specificity [12]. Many studies used NPs as vehicles to deliver drugs for improvement of their therapeutic efficacy [13-15]. NPs can act as drug carriers that can modulate pharmacokinetics, increase bioavailability and target release with minimal toxic effects [16]. 
The use of anti-Toxoplasma drugs loaded with NPs has proved its effectiveness in previous research. By reviewing the researchers who used the various NPs to treat the experimental toxoplasmosis by loading them with antitoxoplasmic drugs or even using them alone, all were positive in favor of treatment of toxoplasmosis. They all supported the efficiency of these molecules in several effects that include higher survival rates of infected animals, reduction of the

inflammatory infiltrate in the liver, reduced the number of brain cysts, ultra-structure deformity of tachyzoites, parasite killing in vitro, inhibition the growth of free tachyzoites and decrease in infectivity, protection from reactivated acute infection beside increased drug bioavailability, controlled drug release, as well as preventing degradation, decreasing toxicity and activating the immune system [17-24]. Biodegradable micro/NPs generated from PLGA have attracted attention due to their clinically proven biocompatibility, especially for immunization purposes [27]. These polymeric particulate delivery systems are able to present antigens and activate both humoral and cellular responses. Particles made from PLGA can be used as a delivery system and also provide adjuvant activity during immunization protocols $[25,26]$.

In an effort to spur the development of treatment regimens with reduced toxicity, the present work was carried out to evaluate the efficacy of spiramycin- loaded PLGANPs versus spiramycin alone in the treatment of toxoplasmosis in the experimentally infected mice.

\section{MATERIAL AND METHODES}

\subsection{Parasite:}

Virulent Toxoplasma gondii (RH strain) tachyzoites was obtained from Medical Parasitology Department, Faculty of Medicine, Alexandria University. Maintenance of the strain was done by serial intraperitoneal injection of tachyzoites in Swiss albino mice (6-8 weeks old, $20 \mathrm{~g}$ weight) every 3-4 days interval. Tachyzoites were collected after 4 days post infection (PI) from the peritoneal exudates and washed three times in phosphate buffer solution (PBS) at $\mathrm{pH}$ (7.4). Then, they were diluted with PBS with $\mathrm{pH} 7.4$ and used for infection of mice at a dose of $10^{3}$ tachyzoites per mouse [28-30].

\subsection{Experimental animals:}

Fifty male albino mice, aged $6-8$ weeks, weighing $20-25 \mathrm{~g}$ was provided by the Schistosome Biological Supply Centre (SBSC) in Theodor Bilharz Research Institute (TBRI). Throughout the study, the animals were housed in well ventilated cages with perforated covers (cleaned every day), supplied with standard pellet food and water. Mice stools were examined conventionally to exclude the presence of parasites [31]. The mice were allowed to adapt to the laboratory environment for one week before the experiment. The experimental mice were divided into five groups according to the treatment regimen (10 mice for each) as follows:

Group1: Non-infected (negative-control G1).

Group2: Infected non-treated (positive-control G2).

Group3: Spiramycin treated G3.

Group4: PLGANPs treated G4.

Group5: Spiramycin loaded PLGANPs treated G5. 
The study was conducted according to the regulations of the ethics committee of Theodor Bilharz Research Institute (TBRI), based on international regulations of animal care.

\subsection{Drugs:}

\subsubsection{Spiramycin preparation:}

The spiramycin drug was manufactured and provided by Pharaonia Pharmaceuticals, Egypt in the form of one and a half milligrams per tablet. Spiramycin $1.5 \mathrm{mg}$ tablet was crushed and dissolved in one $\mathrm{ml}$ distilled water. It was orally given to mice in a dose of $200 \mathrm{mg} / \mathrm{kg} /$ body weight per mouse [33].

\subsubsection{PLGA preparation:}

PLGA was supplied by Sigma Chemical CO, Cat No: 805726, USA with an average molecular weight of 46,7 whose copolymer ratio of DL-lactide to glycolide is 50:50 as indicated. PLGA NPs were prepared according to nanoprecipitation technique by Fessi et al., [34]. It was orally given to mice in a dose of $200 \mu \mathrm{g} / \mathrm{kg} /$ day per mouse.

\subsubsection{Loading spiramycin with PLGANPs:}

Spiramycin-loaded PLGANPs was done by the addition of PLGANPs solution to spiramycin solution at concentration (200 $\mathrm{mg} / \mathrm{ml}$ ). Spiramycin -loaded PLGANPs was separated from aqueous suspension by centrifugation at $14,000 \mathrm{rpm}$ and $14^{\circ} \mathrm{C}$ for 30 minutes. The supernatant was collected and protein content (free spiramycin) in supernatant was determined by the Bradford protein assay spectrophotometric method at $595 \mathrm{~nm}$ [35].

Spiramycin-loaded PLGANPs were at dose $(200 \mu \mathrm{g} / \mathrm{kg} /$ day $)$ PLGANPs containing 200 $\mathrm{mg} / \mathrm{kg} /$ day spiramycin per mouse.

\subsection{Animal infection:}

The numbers of Toxoplasma gondii tachyzoites were detected and counted by taking $50 \mu$ of peritoneal wash (estimated by micro pipette) and put on a glass slide then examined by light microscope at high power (100x objective lens). It was a must to repeat the counting three time to take the average using this equation (count $/ 50 \mu 1 \times 20)=$ count /ml [6].

Subcutaneous injection of each mouse by Toxoplasma gondii tachyzoite in a dose about $10^{3}$ tachyzoite/ mouse was done according to Eissa et al., [32].

\subsection{Drugs administration:}

Mice were fasted for $1 \mathrm{~h}$ before receiving the drugs. Each drug regimen was administrated orally for each specific group once daily by gavage in a volume of $0.2 \mathrm{ml}$ by means of a feeding needle. The drug regimens started from the first day to the seventh day post infection (PI).

\subsection{Animal Sacrificing:}

At the end of the seventh days after infection and receiving treatment, the surviving mice were sacrificed by rapid decapitation and autopsied. Blood was collected from each mouse into tubes, and centrifuged at $3000 \mathrm{rpm}$ for 5 minutes. The serum was removed in clean tubes and stored at $20 \mathrm{C}^{\circ}$. Each mouse was fixed in dissecting tray; a small slit was carefully made in the mid-line of abdominal wall, muscles and peritoneum. Peritoneal cavity was washed by about $1 \mathrm{ml}$ of sterile normal saline using $3 \mathrm{ml}$ sterile syringe with withdrawal of peritoneal fluid. Internal tissues (liver, spleen, kidney, intestine) from each mouse were removed in clean tubes and preserved in $10 \%$ formalin.

2.7. Evaluation of the efficacy of the tested drug regimens: 
2.7.1. Estimation of the mortality rate (MR) Eissa et al., [32]

Number of dead mice at the

$\mathrm{MR}=$ sacrifice time

Number of mice at the beginning of the experiment $\mathrm{x} 100$

\subsubsection{Parasitological examination:}

All the infected mice were subjected to the following:

Estimation of the tachyzoites count in:

- $\quad$ Peritoneal fluid: Fifty $\mu$ of peritoneal wash (estimated by micro pipette) put on a glass slide was examined by light microscope at high power (100x objective lens) to detect and count tachyzoites. It was a must to repeat the counting three times to take the average. The equation (count $/ 50 \mu 1 \times 20=$ count $/ \mathrm{ml}$ ) was used to calculate the count [6].

- Liver and spleen: Impression smears were made from liver and spleen, stained with Giemsa stain. Counting of T. gondii tachyzoites in different tissue smears were carried out using oil immersion objectives $(100 x)$ lens. The mean of ten different fields from each organ of each mouse were calculated [36].

\subsubsection{Assessment of drugs toxicity in tissues:}

Assessment the drugs toxicity in liver, kidney and intestine were done by estimation of GSH [37] and MDA [38] using colorimetric method. Kit of Bio diagnostic (Cat.No.GR. 25 11, Egypt) was used for estimation of GSH level and kit of Bio diagnostic (Cat. No. MD. 25 29, Egypt) was used for estimation of MDA.

\subsubsection{Immunological evaluation in serum samples of tested mice:}

- Determination of gamma interferon serum level (IFN $\gamma$ ) was done by quantitative sandwich enzyme immunoassay technique using Kit of Quantikine® Mouse IFN- $\gamma$ (Catalog Number SMIF00, USA \& Canada R\&D Systems, Inc.). The optical density (O.D.) was read at $450 \mathrm{~nm}$ using a micro titer plate reader within 30 minutes.

- Determination of tumor necrosis factor (TNF- $\alpha$ ) was done by quantitative sandwich enzyme immunoassay technique using Kit of Quantikine $\AA$ Mouse TNF- $\alpha$ (Cat No: MTA00B, USA \& Canada R\&D Systems, Inc.). The optical density (O.D.) was read at $450 \mathrm{~nm}$ using a micro titer plate reader within 30 minutes.

- Determination of IgM antibodies was performed by Indirect ELISA with some modifications according to Engvall and Perlmann [39]. The absorbance was measured at $492 \mathrm{~nm}$ using ELISA reader within 30minute (Bio-Rad microplate reader, Richomond, Co). Toxoplasma antigen was kindly supplied by the Department of Immunoparasitology and Immunology (TBRI).

\section{Statistical Analysis}

Data were collected, revised, coded and entered to the Statistical Package for Social Science (IBM SPSS) version 23. The quantitative data were presented as mean, standard deviations. Also, qualitative variables were presented as number and percentages. The comparison between groups regarding qualitative data was done by using Chi-square test. The comparison between more than two groups with quantitative data and parametric distribution were done by using One Way ANOVA test followed by post hoc analysis using 
LSD test. The comparison between more than two paired groups with quantitative data and parametric distribution were done by using Repeated Measures ANOVA. P. value < 0.05 was considered statistically significant.

\section{RESULTS:}

\subsection{Mortality rate:}

The least mortality rate was in spiramycin treated group3 $(10 \%)$ in comparison to any of the other infected groups $(2,4,5)$ with $20 \%$ for each and $0 \%$ for negative group 1 as shown in Fig.1.

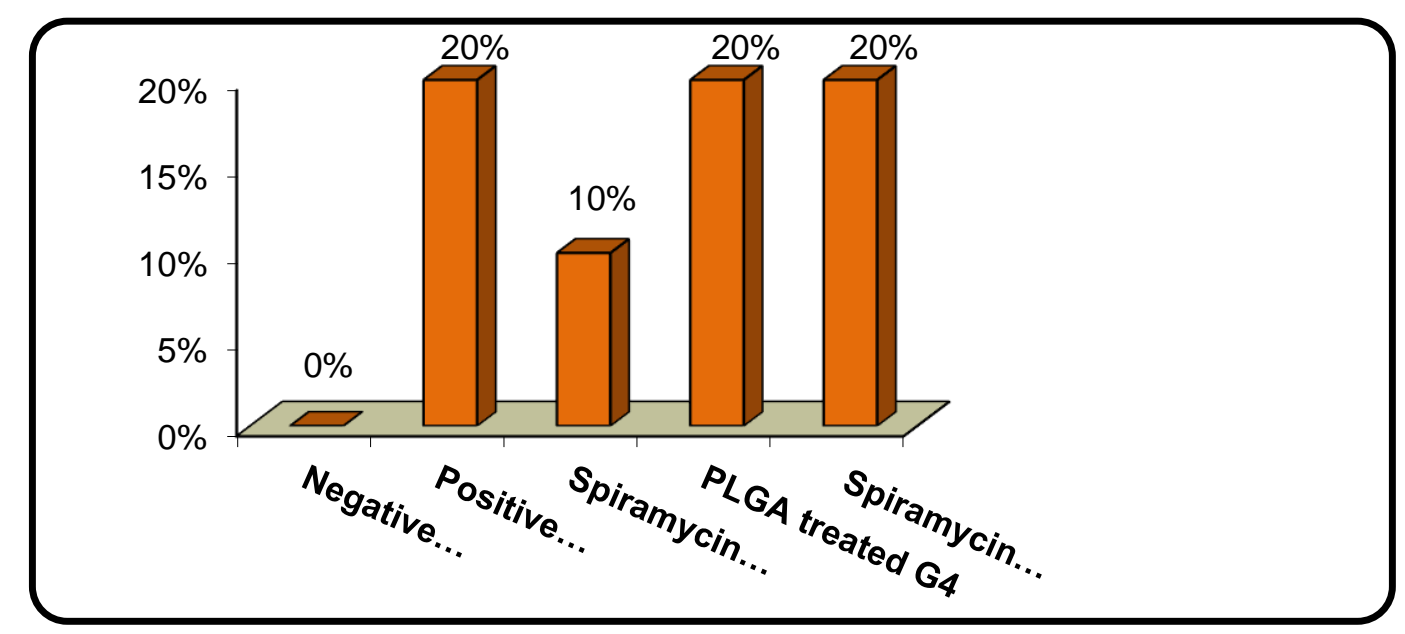

Figure 1: The mortality rate of mice after $T$. gondii tachyzoite infection in all studied groups.

\subsection{Estimation of the tachyzoites count in peritoneal fluid, liver and spleen:}

The spiramycin loaded PLGANPs treated group5 achieved the lowest mean number $(2428.00 \pm 345.21,341.00 \pm 42.02,470.00 \pm$ 66.00 respectively), followed by spiramycin treated group3 $(4036.00 \pm 624.02,606.00 \pm$
$70.43,824.00 \pm 101.35$ respectively) then PLGANPs treated group4 (7903.00 \pm 2240.64 , $795.00 \pm 160.92, \quad 1287.00 \pm 108.22$ respectively) as shown in Fig.2. 


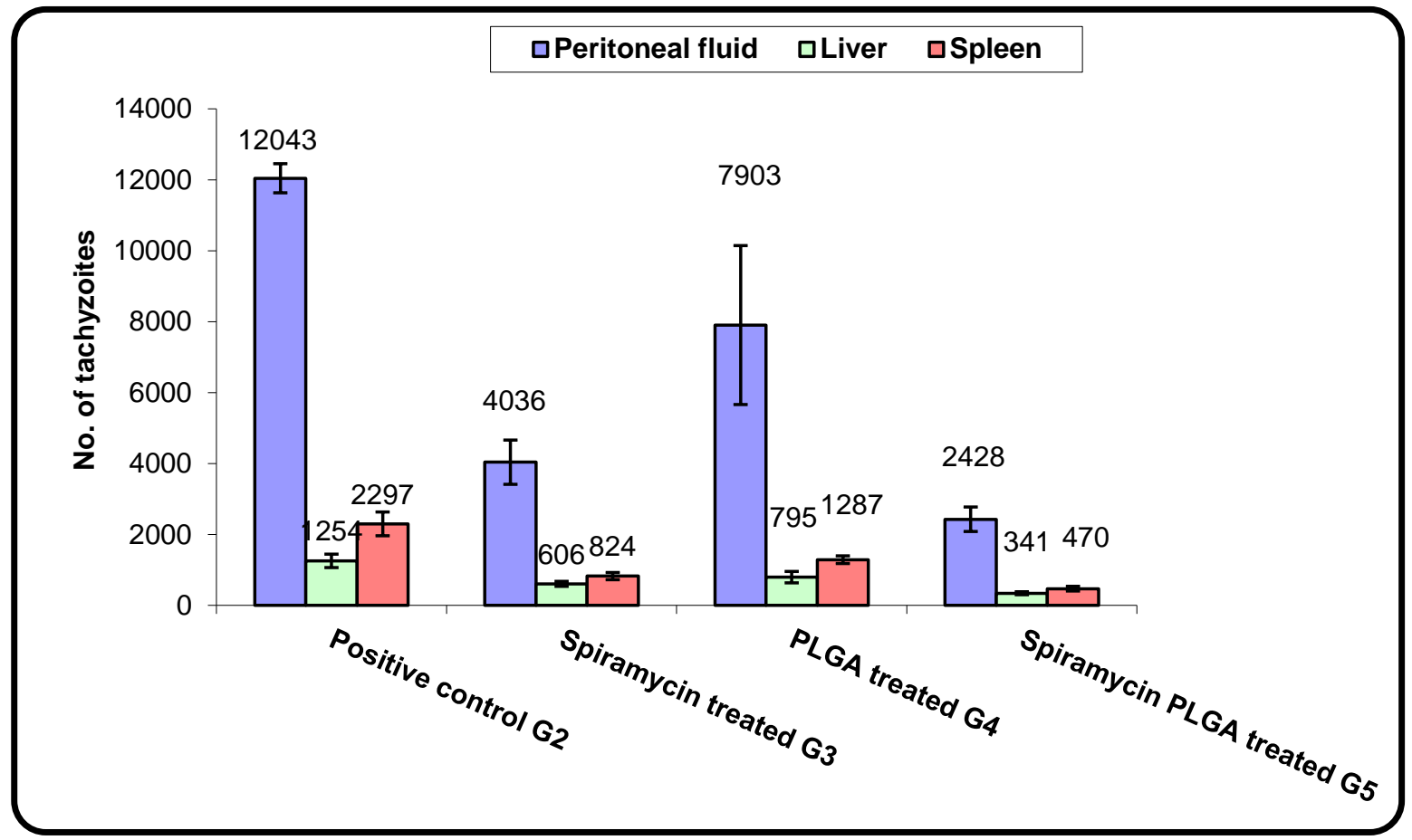

Figure 2: Mean numbers of $T$. gondii tachyzoites in different tissues among infected groups.

\subsection{Assessment of drugs toxicity in tissues:}

\subsubsection{Measurement of GSH level:}

The highest mean levels of GSH in liver, intestine and kidney tissues are recorded at non infected group1 $(4.85 \pm 0.52,3.35 \pm 0.4$, $3.04 \pm 0.43$ respectively). These levels have decreased significantly in infected non treated group2 $(2.37 \pm 0.38,1.51 \pm 0.31,1.18 \pm 0.33$ respectively) reflecting the maximum toxicity. It started to rise in spiramycin treated group3 $(3.29 \pm 0.26,2.22 \pm 0.33,2 \pm 0.32$ respectively) then PLGANPs treated group4 $(3.96 \pm 0.54,2.32 \pm 0.39,2.05 \pm 0.27$ respectively) and reached the maximum rise in spiramycin loaded with PLGA NPs treated group5 $(4.58 \pm 0.42,2.96 \pm 0.5,2.29 \pm 0.25$ respectively) with no significant difference of the later in comparison to non-infected group as shown in Fig.3. 


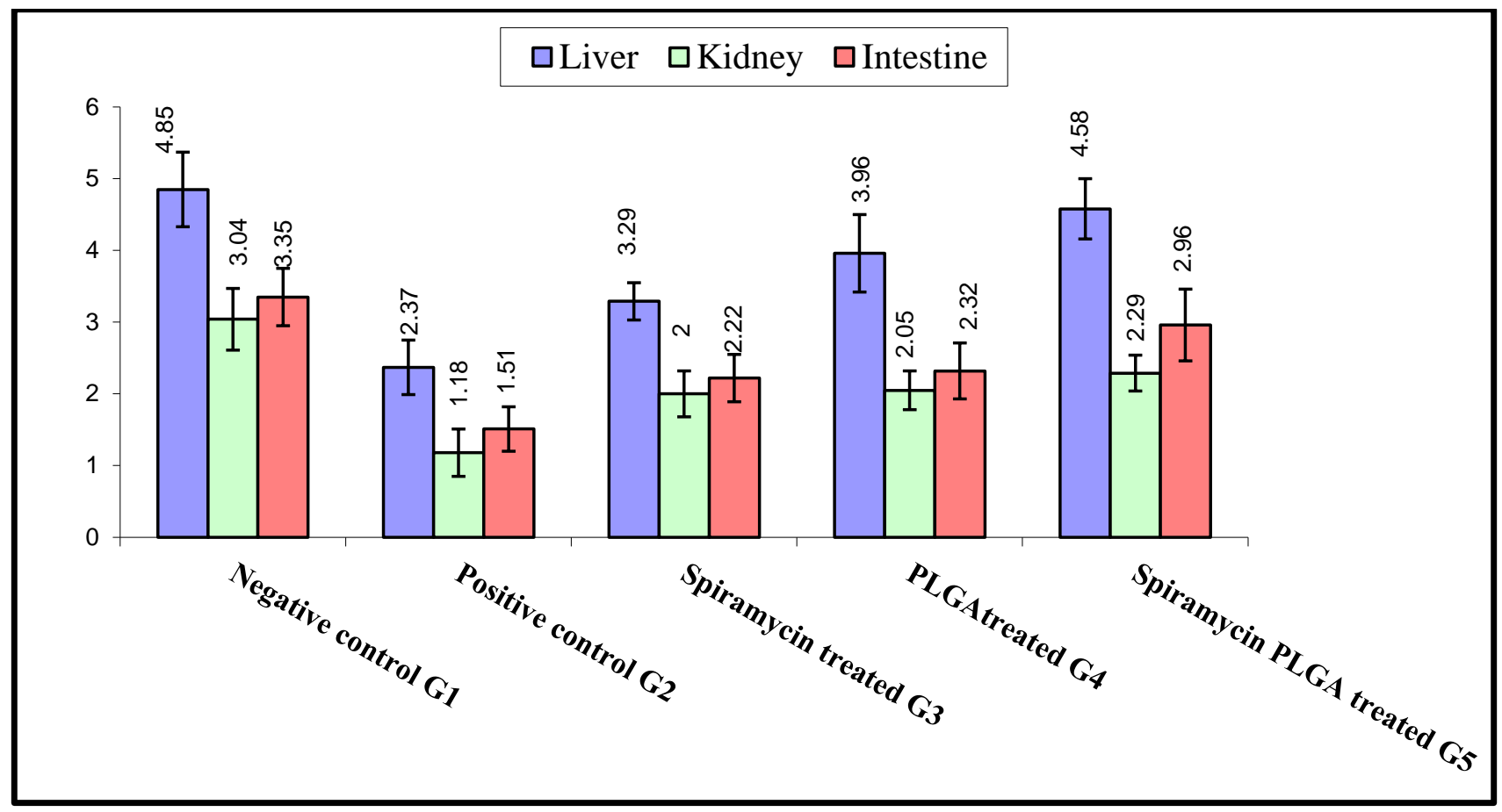

Figure 3: Mean levels of GSH in different tissues in different studied groups.

\subsubsection{Measurement of MDA level:}

The lowest mean levels in liver, kidney and intestine tissues in non-infected group1 (42.98 $\pm 1.79, \quad 36.08 \pm 3.09,29.11 \pm 1.31$ respectively). These levels have elevated significantly in infected non treated group2 $(68.9 \pm 1.94,60.02 \pm 2.42,51.03 \pm 0.69$ respectively) reflecting the maximum toxicity. It started to decrease in PLGA treated group4 $(51.53 \pm 1.03,46.15 \pm 0.59,55.01 \pm$ 1.75 respectively) then spiramycin treated group3 $(55.78 \pm 1.27,43.14 \pm 1.15,50.98 \pm$ 1.81 respectively) and reached the maximum reduction in spiramycin loaded PLGA NPs treated group5 $(46.8 \pm 1,35.88 \pm 1.24,41.02$ \pm 1.25 respectively) as shown in Fig.4.

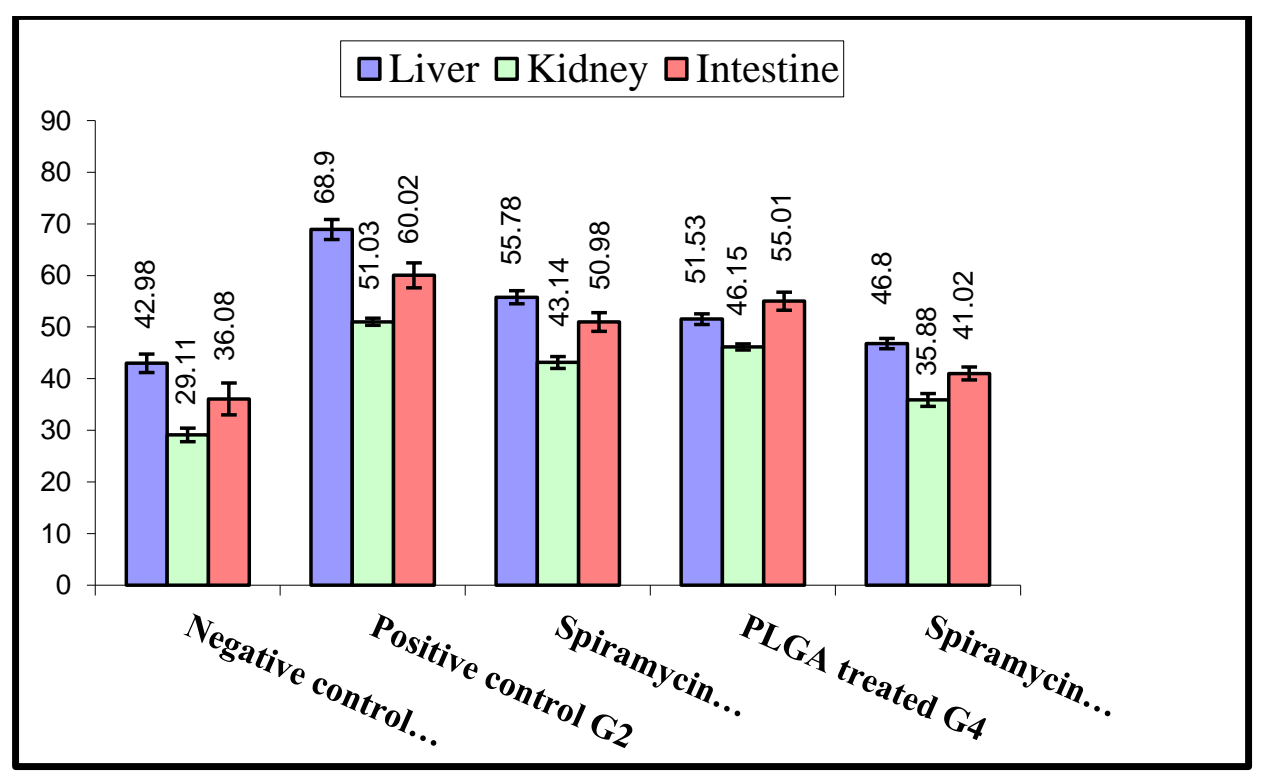

Figure 4: Mean levels of MDA in different tissues in different studied groups. 


\subsection{Immunological evaluation in serum} samples of tested mice:

\subsubsection{Determination of IFN- $\gamma$ :}

The mean level of optical density (OD) reading of IFN- $\gamma$ in the serum samples was at its highest level in the spiramycin loaded
PLGA group5(780.30 \pm 7.26$)$ in comparison to spiramycin treated group3(691.71 \pm 4.62$)$ then PLGA treated group4 (470.04 \pm 3.43$)$ and lastly infected non treated group2 (409.84 \pm 3.42 ) while the lowest level was for noninfected group1 $(133.65 \pm 4.49)$ as shown in Fig.5.

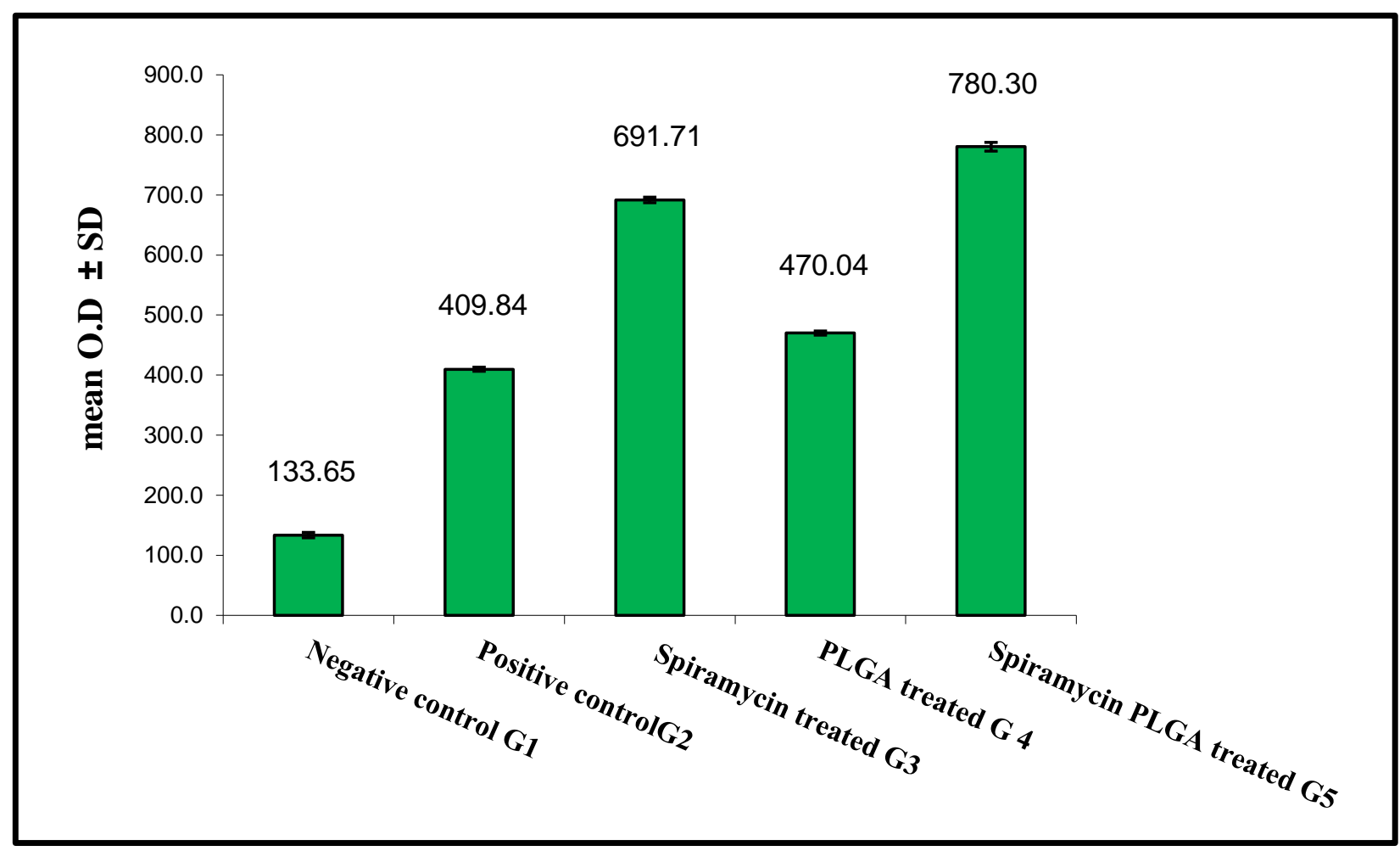

Figure 5: Mean levels of optical density readings of IFN- $\gamma$ at $450 \mathrm{~nm}$ in all studied groups.

\subsubsection{Determination of TNF- $\alpha$ :}

The OD mean value of TNF- $\alpha$ in the serum samples of the different studied groups was at its highest level in the infected non treated group2 $(2654.90 \pm 78.34)$. Among the treated groups, the lowest significant mean level was recorded for spiramycin loaded PLGANPs group5 (1241.70 \pm 38.94$)$ in comparison to in spiramycin treated group3 $(1495.20 \pm 6.14)$ then PLGANPs treated group4 (2158.30 \pm 44.96) as shown in Fig.6. 


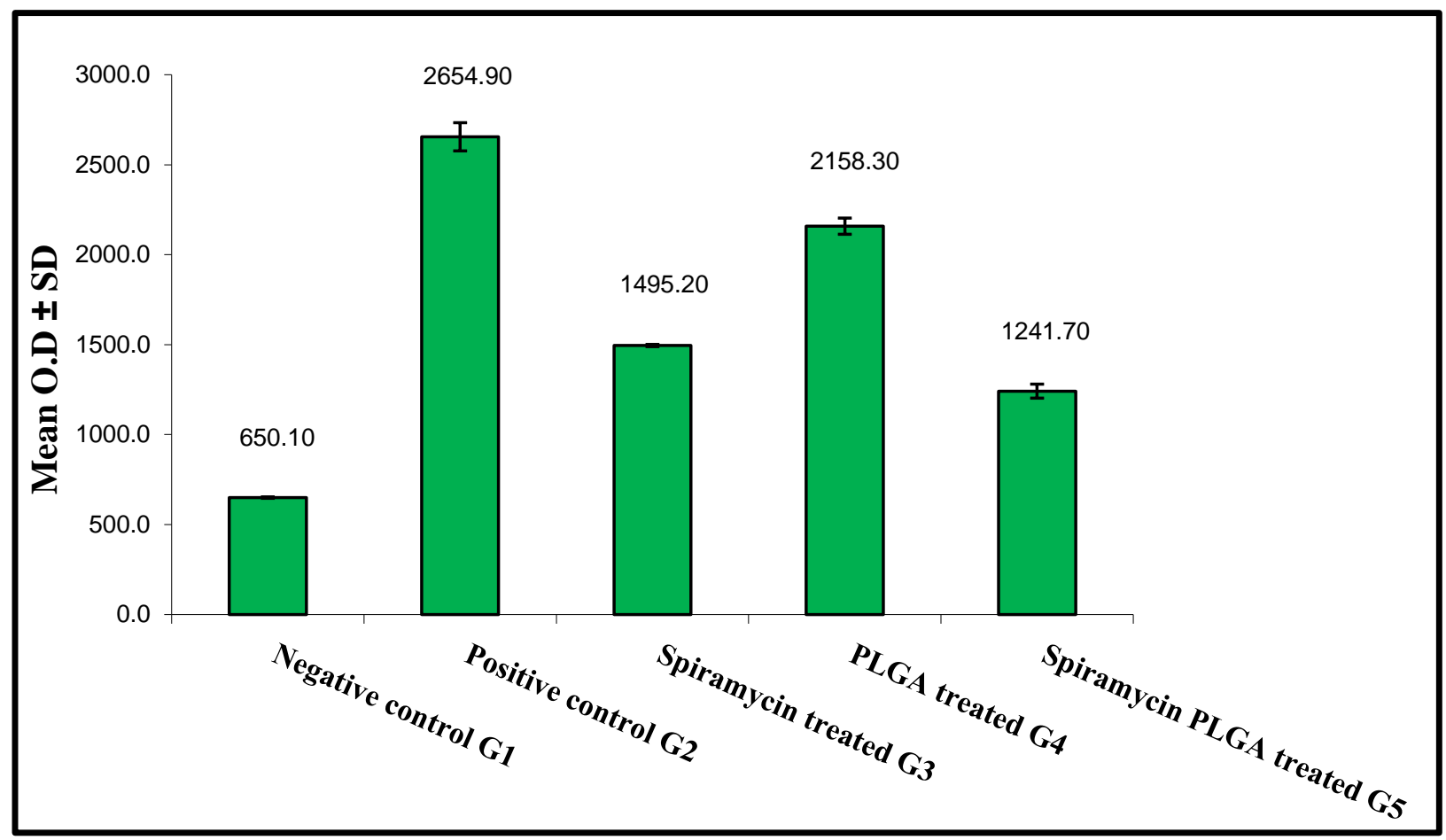

Figure 6: Mean levels of optical density readings of TNF- $\alpha$ at $450 \mathrm{~nm}$ in all studied groups.

\subsubsection{Determination of IgM:}

The OD mean value of IgM in the serum samples of studied mice was at its highest level in the infected non treated group2 $(1.40$ \pm 0.04 ), while the lowest significant mean level was recorded for spiramycin loaded with PLGA NPs treated group5 $(0.60 \pm 0.01)$ in comparison to spiramycin treated group3 $(0.74 \pm 0.01)$ then PLGA treated group4 (0.97 $\pm 0.01)$ as shown in Fig.7.

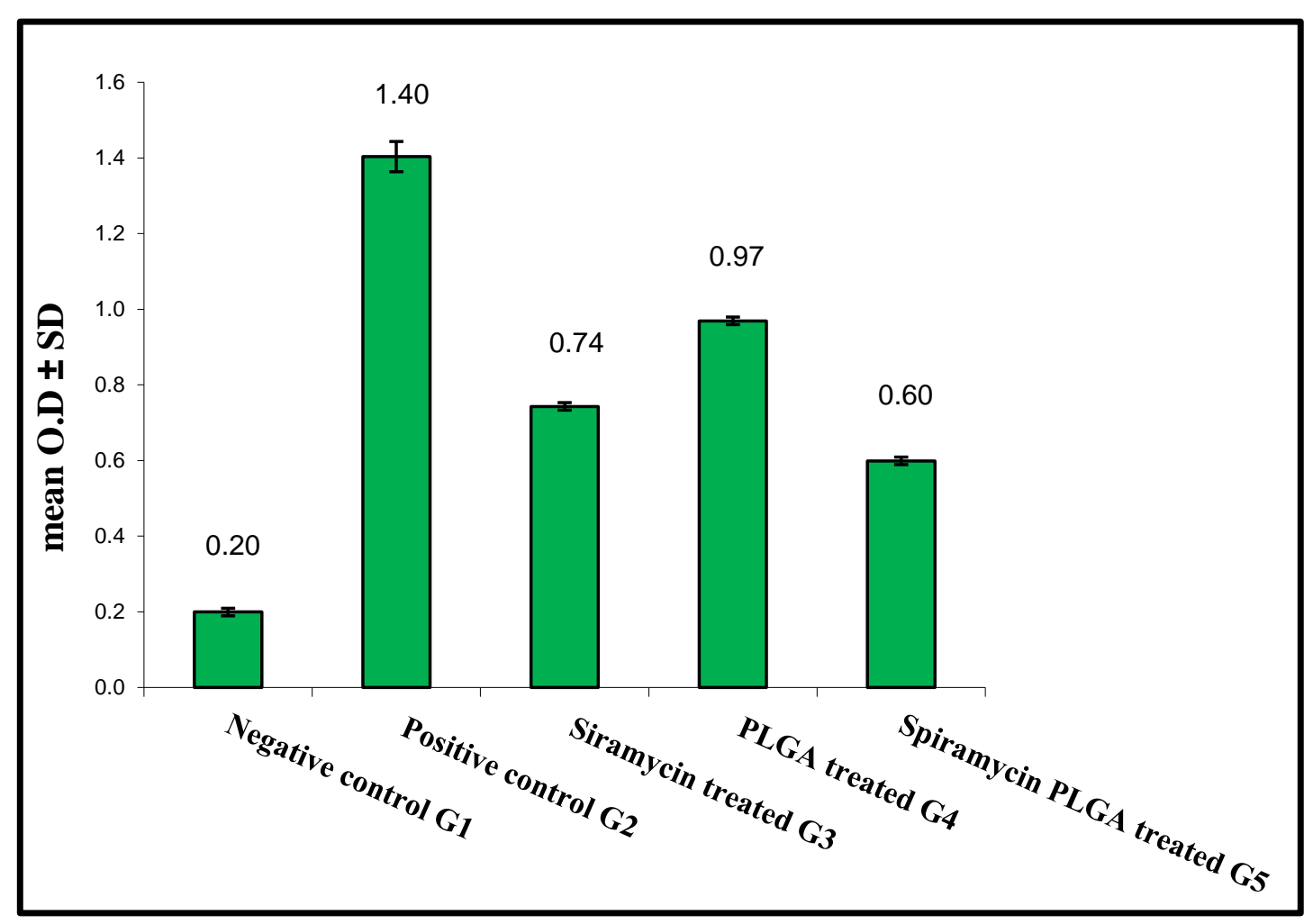

Figure 7: Mean levels of optical density readings of IgM at $492 \mathrm{~nm}$ in all studied groups. 


\section{DISCUSSION:}

Nanoparticles have been used widely in previous studies as vehicles to deliver drugs or vaccines and were tried in helminthic parasites as; Brugia malayi and Echinococcus granulosus and also in parasitic protozoa as; T. gondii, Leishmania major and malaria $[13,33,40,41]$.

Nanosuspensions were prepared from some anti-toxoplasmic drugs in order to overcome their low absorption [42-44]. In this study, spiramycin as a known antitoxoplasmic drug was loaded with PLGA NPs and its therapeutic potential was estimated in treatment of murine toxoplasmosis.

At the present study, the least mortality rate (Fig. 1) was in spiramycin treated group3 with no significant difference in comparison to any of the other infected groups $(2,4,5)$ and negative group1. Spiramycin (100 and 200 $\mathrm{mg} / \mathrm{kg} /$ day) was recorded with some dependent prolonged survival rate in mice infected with $2 \times 10^{2}$ tachyzoites of the $\mathrm{RH}$ strain [45]. but not with complete protection against death. In contrast to the present result are Etewa et al; El-Temsahy et al; Sordet et al. $[1,15,46]$ who recorded significant decrease mortality or increase survival rates in murine toxoplasmosis after treatment with drug loaded NPs such as (spiramycin-loaded chitosan NPS (SLCNs), chitosan nanospheres encapsulated with Toxoplasma lysate vaccine and atovaquone-loaded nanocapsules) respectively.

By counting the tachyzoites (Fig. 2) in the peritoneal wash, liver and spleen smears in the examined groups, it was found that spiramycin loaded PLGANPs treated group5 achieved the lowest mean number followed by spiramycin treated group3 then PLGANPs treated group4 with a significant statistical difference using $\mathrm{F}$ test and post hoc analysis $(\mathrm{P}<0.05)$ between all studied groups. The highest mean level was recorded for infected non treated group2. This means that spiramycin loaded PLGANPs treated group5 had the highest impact on reducing the number of the parasites in different tissues. Putting in mind that the spiramycin treated group3 achieved a lower significant mean number of parasites in all tissues compared to the PLGANPs treated group4 $(\mathrm{P}<0.05)$. therefore, it could be expected that the reduction of tachyzoites number in different tissues by the combined treatment is mainly due to improved performance of spiramycin after being loaded PLGANPs. This is in agreement with Etewa et al. [1] who noticed that impression smears made from liver and spleen revealed highly significant decrease in the number of Toxoplasma tachyzoites in mice groups treated with spiramycin-loaded chitosan NPs as compared to the other subgroups (infected control, infected and received chitosan NPS (CS NPs) and infected 
and treated with spiramycin). Also, Gaafar et al. [6] noticed that impression smears made from liver and spleen revealed similar highly significant reduction in the number of Toxoplasma tachyzoites in mice treated by silver NPs alone or combined with chitosan NPs.

Nanomaterials associated with molecules or drugs for experimental toxoplasmosis studies has shown improvement in one or more aspects as reducing parasitic load in liver and spleen or even absence of parasites in the blood and brain, deformity in tachyzoites, increased bioavailability of the conjugated drug, amelioration of cellular infiltrate in infected tissues, higher survival rate of the infected animals, in vitro inhibition of the growth of free tachyzoites , decrease the number of infected macrophages and parasites per cell, protection of mice from reactivated acute infection [47]. Among these NPs used alone or loaded with molecule or drugs are silver NPs [6], gold NPs [17,18], polymeric NPs of chitosan [6], polymeric nanocapsules of alginate-chitosan [20], Liposomes [14.22,48], core-shell latex NPs [19], nanosuspensions $[4,44,50,51]$, core lipid nanocapsules [52], drug-dendrimer complex [53], hydroxypropyl- $\beta$-cyclodextrin [23] and cyclodextrin $[23,24]$.

An ideal drug for treatment would show low oxidative stress and accordingly low toxicity. The present study assessed GSH and
MDA as keys of oxidative stress related molecules in mice liver, kidney and intestine after administration of different drug regimens.

GSH, an endogen-originated peptide, can be synthesized in the liver without need for genetic data, GSH is an antioxidant, a powerful detoxifier and helps activate the better known antioxidants, vitamin $\mathrm{C}$ and vitamin E. It is an important constituent of intracellular protective mechanisms against a number of noxious stimuli including oxidative stress [54]. Oxidative stress is related to systemic glutathione deficiency while protection is indicated by higher levels in the tissues. The normal range for reduced GSH is $3.8-5.5 \mathrm{umol} / \mathrm{L}$ in plasma, according to the Health Diagnostics and Research Institute [55].

The highest mean levels of GSH in liver, intestine and kidney tissues (Fig. 3) were recorded for non-infected group1. These levels have decreased significantly in infected non treated group2 reflecting the maximum toxicity. It started to rise in spiramycin treated group3 then PLGANPs treated group4 and reached the maximum rise in spiramycin loaded with PLGANPs treated group5 with no significant difference of the later in comparison to non-infected group indicating the minimal toxicity in this group.

MDA is an end-product of lipid peroxidation, a well-established mechanism of cellular injury. So, MDA is used as an 
indicator of oxidative stress in cells and tissues [56]. MDA as an oxidative marker according to the present data - was found with the lowest mean levels in liver, kidney and intestine tissues (Fig. 4) in non-infected group1. These levels have elevated significantly in infected non treated group2 reflecting the maximum toxicity. It started to decrease in PLGA treated group4 then spiramycin treated group3 and reached the maximum reduction in spiramycin loaded PLGANPs treated group5 with significant differences between studied groups upon using $\mathrm{F}$ test and post hoc analysis. Similar results are that of Miricescu et al. [57], who assessed oxidative stress by estimation of GSH and MDA levels in healthy rats after acute administration of PLGANPs. The obtained data showed GSH levels were decreased and MDA levels increased in spleen and liver in comparison to their respective controls with no statistical significance between the two analyzed groups as regard GSH but as regard to MDA the absence of significant difference was recorded for spleen only. This current study showed that with the use of PLGA NPs the degree of toxicity decreases and even improves to the extent of approximating that of healthy control. This is in agreement with Semete et al. [58] who observed high doses of PLGA did not lead to any tissue lesions as compared to the same high dose of $\mathrm{ZnO}$ (zinc oxide) NPs that led to toxicity in mice.
Both Innate and adaptive immunity play critical roles in protecting against Toxoplasma gondii infection. A strong cellular immune response was elicited during toxoplasmosis showing significant production of IFN- $\gamma$ and IL-2 associated with Th1 type response [59]. IFN- $\gamma$ is the first cytokine implicated in resistance to $T$. gondii and remains the keystone of protective immunity to Toxoplasma [60]. The secretion of INF- $\gamma$ increases the phagocyte activity of macrophages and the cytotoxic activity of CD8 TL. However, IFN- $\gamma$ triggers the conversion of tachyzoites into bradyzoites at the same time preventing their rupture [61].

This study showed higher significant production of the IFN- $\gamma$ (Fig. 5) in infected non treated group2 (409.84 \pm 3.42) in comparison to the non-infected group1 $(133.65 \pm 4.49)$. This is in agreement to Filisetti \& Candolfi, [60] who stated that increased production of IFN- $\gamma$ is strongly correlated with parasite virulence and enhanced apoptosis. Our data showed that the mean level of OD reading of IFN- $\gamma$ in the serum samples (Fig. 5) was at its highest level in the spiramycin loaded PLGA group5 in comparison to spiramycin treated group 3 then PLGA treated group4 and lastly infected non treated group2 while the lowest level was for non-infected group1. This indicates an enhancement of immunity of spiramycin loaded PLGA group5 which showed a significant better level of IFN- $\gamma$ than other groups. The Increase in IFN- $\gamma$ could be 
correlated with the significant highest tachyzoites reduction in the same group. On support of the present results is Liu et al. [61] who found that $\mathrm{PH}$ - responsive PLGA NPs have impact in stimulating cellular and humoral immune response that allowed it to be used in prevention of immune system disorders and inflammatory processes. Mouse immunization with $\mathrm{pH}$ - responsive PLGANPs induced greater lymphocyte activation, more antigen-specific CD8 $\mathrm{T}$ cells, stronger cytotoxic capacity (IFN- $\gamma$ and granzyme B), enhanced antigen-specific IgG antibodies, and higher serum IgG2a/IgG1, indicating cellular immunity. Also, Hamad et al. [62] found that the highest level of IFN- $\gamma$ was in the mice group treated by Chitosan NPs plus spiramycin compared with infected control group. Other NPs administration as Ag NPs alone or combined with CS NPs achieved the highest level of IFN- $\gamma$ in treated mice [6].

In toxoplasmosis TNF- $\alpha$ would appear to be essential for macrophage activation and inhibition of parasite replication, but this action can only be exerted in synergy with IFN- $\gamma$. This protective action is exerted in mice in both the acute and chronic phase of the disease. In addition, TNF- $\alpha$ - like IL-12, another monocyte macrophage product stimulates the production of IFN- $\gamma$ by $\mathrm{NK}$ cells, which play a crucial role in the early non-specific response during toxoplasmosis [64].
In the present study, the OD mean value of TNF- $\alpha$ in the serum samples of the different studied groups (Fig. 6) was at its highest level in the infected non treated group2 (2654.90 \pm 78.34). This result agrees with the findings of Khalil \& Rashwan. [65] who reported acute infection was associated with the highest levels of TNF- $\alpha$ indicating that it plays a role in the pathogenesis of acute toxoplasmosis [66]. Among the treated groups, the lowest significant mean level was recorded for spiramycin loaded PLGANPs group5 in comparison to in spiramycin treated group3 then PLGANPs treated group4. On support of our explanation is Hamad et al., [67] who recorded reduction in level of TNF- $\alpha$ cytokine in mice infected by toxoplasma tachyzoites after treatment with spiramycin plus chitosan. In contrary to the present results is Liu et al. [68] who reported that Ag NPs are potent enhancer to the immune system. They recruit leukocytes and increase both TNF- $\alpha$ and IFN- $\gamma$ in mouse abdominal cavity and also up-regulate the MHC II molecules expression of peritoneal macrophages.

IgM are the first antibodies to be promoted after T. gondii infection. These immunoglobulins are the best activators of the complement system. They enable excellent agglutination and have a high level of cytotoxicity. The major target antigens of these $\operatorname{IgM}$ are the surface proteins of the parasite [61]. Couper et al. [69] Demonstrated an important inhibitory role for $\operatorname{IgM}$ in limiting tachyzoite host cell invasion and 
systemic dissemination during virulent $T$. gondii RH infection. With specific relevance to $T$. gondii infection, IgM has been shown to increase tachyzoites killing by neutrophils and is a potent activator of complement [60].

This study recorded the same gradient observed of OD mean value TNF- $\alpha$ for OD mean value of $\operatorname{IgM}$ among all studied groups (Fig. 7) where the OD mean value of IgM in the serum samples of studied mice was at its highest level in the infected non treated group2, while the lowest significant mean level was recorded for spiramycin loaded with PLGANPs treated group5 in comparison to spiramycin treated group3 then PLGA treated group4. Consistent with the result of this proposition the previous research of Brinkmann et al. [71] who found that Toxoplasma-specific IgM and IgG levels were lower in sulfadiazine treated immunocompetent and B-cell-deficient mice than untreated mice following infection of all with 20 cysts of Me 49 (avirulent strain of $T$. gondii). This study found that the treatment with spiramycin loaded with PLGA did not improve levels of TNF- $\alpha$ and $\operatorname{IgM}$ in the infected treated mice. If we link the reduction of the number of tachyzoites achieved by treatment with the levels of TNF- $\alpha$ and IgM we could assume that the immediate treatment after infection had a potent lethal effect on injected tachyzoites thus limited the stimulant antigenicity with weaker immune response. This limiting effect was more pronounced in spiramycin loaded with PLGA group5 in comparison to other infected groups $(2,3,4)$ with significant difference $(\mathrm{P}<0.05)$.

To our knowledge, this is the first research that has been exposed to the effect of spiramycin loaded with PLGA nanoparticles in the treatment of murine toxoplasmosis.

In conclusion, the study supports the effectiveness of spiramycin after being loaded by PLGA NPs in controlling the acute murine toxoplasmosis with the minimal toxicity.

\section{Reference:}

1. Etewa, S.E.; Abo El-Maaty, D.A.; Hamza, R.S.; Metwaly, A.S.; Sarhan, M.A.; Abdel-Rahman, S.A. and Fathy, G.M. (2017): Assessment of spiramycinloaded chitosan nanoparticle treatment on acute and chronic toxoplasmosis in mice. Indian Society for Parasitology. J. Parasit. Dis., 42(1):102-113.

2. Neville, A.J.; Zach, S.J.; Wang. X.; Larson, J.J.; Judge. A.K.; Davis, L.A. et al., (2015): Clinically available medicines demonstrating antiToxoplasma activity. Antimicrob. Agents Chemother., 59(12):7161-9.

3. Garin, J.P. and Eyles, D.E. (1958): Le traitement de la toxoplasmose experimentale de la souris par la spiramycine. Presse Méd., 66: 957-958.

4. Montoya, J.G. and Remington, J.S. (2008): Management of Toxoplasma gondii infection during pregnancy. Clin. Infect. Dis.,47(4):554-566.

5. Wang, J. and Leung, D. (2009): Determination of spiramycin and neospiramycin antibiotic residues in raw milk using LC/ESI-MS/MS and solidphase extraction. J. Sep. Sci., 32(4):681-8.

6. Gaafar, M.R; Mady, R.F.; Diab, R.G. and Shalaby, T.I. (2014): Chitosan and silver nanoparticles: promising anti- 
Toxoplasma agents. Exp. Parasitol., 143:30-38.

7. Wise, R. (1993): Clinical Pharmacokinetics of spiramycin. Clinical Drug Investigation, Volume 6, Supplement 1, pp 29-34.

8. Dino, G.P. (2017): The macrolide antibiotic renaissance. J. Pharmacol., 174(18): 2967-2983.

9. Kuhlmann, F. and Fleckenstein, J.(2017): Antiparasitic Agents in Infectious Diseases (Fourth Edition), 1345-1372.

10.Liversidge, G.G. and Cundy, K.C. (1995): Particle size reduction for improvement of oral bioavailability of hydrophobic drugs: I. Absolute oral bioavailability of nanocrystalline danazol in beagle dogs. Int. J. Pharm., 125:91-97.

11.Duncan, R. (2005): The dawning era of polymer therapeutics. Nature Reviews Drug Discovery, 2(5), 347-360.

12.Akerman, M.E.; Chan, W.C.; Laakkonen, P.; Bhatia, S.N. and Ruoslahti, E. (2002): Nanocrystal targeting in vivo. Proc. Natl. Acad. Sci. USA., 99(20):12617-21.

13.Jiang, S.; Hua, E.; Liang, M.; Liu, B. and Xie, G. (2013): A novel immunosensor for detecting Toxoplasma gondii-specific IgM based on Goldman nanoparticles and graphene sheets. Colloids Surf. B. Bio interfaces, 101:481486.

14.El-Zawawy, L.A.; El-Said, D.; Mossallam, S.F.; Ramadan, H. and Younis, S.S. (2015a): Triclosan and triclosan-loaded liposomal nanoparticles in the treatment of acute experimental toxoplasmosis. Exp. Parasitol., 149:5464.
15.El-Temsahy, M.M.; El Kerdany, E.D.; Eissa, M.M.; Shalaby, T.I.; Talaat, I.M. and Mogahed, N.M. (2016): The effect of chitosan nanospheres on the immunogenicity of Toxoplasma lysate vaccine in mice. J. Parasit. Dis., 40(3):611-626.

16. Khalil, N.M.; de Mattos, A.C.; Carraro, T.C.; Ludwig, D.B. and Mainardes, R.M. (2013):

Nanotechnological strategies for the treatment of neglected diseases. Curr. Pharm. Des., 19(41):7316-7329.

17. Pissuwan, D.; Valenzuela, S.M.; Miller, C.M. and Cortie, M.B. (2007): A golden bullet? Selective targeting of Toxoplasma gondii tachyzoites using antibody-functionalized gold nanorods. Nano. Lett.,7:3808-3812.

18. Pissuwan, D.; Valenzuela, S.M.; Miller, C.M.; Killingsworth, M.C. and Cortie, M.B.(2009): Destruction and control of Toxoplasma gondii tachyzoites using gold nanosphere/antibody conjugates Small. 5(9):1030-4.

19. Leyke,S.; Köhler-Sokolowska, W.; Paulke, B.; and Wolfgang, P.(2012): Effects of nanoparticles in cells infected by Toxoplasma gondii. ePolymers. 12(1):647-663.

20. Anand,N.; Sehgal, R.;Kanwar,R.; Du bey,M.L.;R.K.and Kanwar,J.R.(2015 ): Oral administration of encapsulated bovine lactoferrin protein nanocapsules against intracellular parasite Toxoplasma gondii. Int. J. Nanomedicine. 10: 6355-6369.

21. El-Zawawy, L.A.; El-Said, D.; Mossallam, S.F.; Ramadan, H.S . 
and Younis, S.S.(2015b): Preventive prospective of triclosan and triclosanliposomal nanoparticles against experimental infection with a cystogenic ME49 strain of Toxoplasma gondii. Acta. Trop., 141:103-11.

22. Si, K.; Wei, L.; Yu, X.; Wu, F.; Li, X.; Li, C. and Cheng, Y. (2016): Effects of (+)-Usnic acid and (+)-Usnic acidliposome on toxoplasma gondii. Exp. Parasitol., 166:68-74.

23. Bottari, N.B.;

Baldissera, M.D.; Tonin, A.A.; Rech, V.C.; Nishihira, V.S.; Thomé, G.R.; Camillo, G. et al. ;(2015 b): Effects of sulfamethoxazoletrimethoprim associated to resveratrol on its free form and complexed with 2hydroxypropyl- $\beta$-cyclodextrin on cytokines levels of mice infected by Toxoplasma gondii. Microb. Pathog., 87:40-4.

24. Bottari, N.B.; Baldissera, M.D.; Tonin, A.A.; Rech, V.C.; Alves, C.B.; D'Avila, F.; Thomé, G.R.et al., (2016): Synergistic effects of resveratrol (free and inclusion complex) and sulfamethoxazole-trimetropim treatment on pathology, oxidant/antioxidant status and behavior of mice infected with Toxoplasma gondii. Microb. Pathog., 95:166-174.

\section{Jiang, W.; Gupta, R.K.; Deshpande,} M.C. and Schwendeman, S.P.(2005): Biodegradable poly(lactic-co-glycolic acid) microparticles for injectable delivery of vaccine antigens. Adv. Drug Deliv. Rev., 10;57(3):391-410.
26. O'Hagan, D.T. and Valiante, N.M. (2003): Recent advances in the discovery and delivery of vaccine adjuvants, Nat. Rev. Drug Discov., 2 :727 - 735.

27. Mundargi, R.C.; Babu, V.R.; Rangaswamy, V.; Patel, P.and Aminabhavi, T.M.( 2008): Nano/micro technologies for delivering macromolecular therapeutics using poly(D,L-lactide-co-glycolide) and its derivatives J Control Release. 125(3):193-209.

28. Eissa, M.M.; El-Azzouni, M.Z.; Mady, R.F.; Fathy, F.M. and Baddour, N.M. (2012): Initial characterization of an autoclaved Toxoplasma vaccine in mice. Exp. Parasitol.; 131:310-316.

29. Chan, J. and Luft, B.J. (1986): Activity of roxithromycin (RU 28965), a macrolide, against Toxoplasma gondii infection in mice. Antimicrob Agents Chemother., 30(2):323-324.

30. Saudi, M.N.; Gaafar, M. R.; ElAzzouni, M. Z.; Ibrahim, M. A. and Eissa, M. M. (2008): Synthesis and evaluation of some pyrimidine analogs against toxoplasmosis. Medicinal Chemistry Research . 17:541.

31. Giarcia, L.S. and Bruckner, D.A. (1977): Macroscopic and microscopic examination of fecal specimens. In: Diagnostic Medical Parasitology, 3rd ed. ASM Press, Washington, DC, pp. 608649.

32. Eissa, M.M.; El-Azzouni, M.Z.; Mady, R.F.; Fathy, F.M. and Baddour, N.M. (2012): Initial characterization of an autoclaved Toxoplasma vaccine in mice. Exp. Parasitol.,131:310-316.

33. Montazeri,M.; Sharif, M.; Sarvi,S.; Mehrzadi,S.; Ahmadpour, E. and Daryani, A.(2017): A Systematic Review of In vitro and In 
vivo Activities of Anti Toxoplasma Drugs and Compounds. Front Microbiol., 8: 25.

34. Fessi, H.; Puisieux, F.; Devissaguet, J.P.; Ammoury, N. and Benita, S. (1989): Nanocapsule formation by interfacial polymer deposition following solvent displacement. Int J Pharm., 55(1): R1-R4.

35. Danesh-Bahreinni, M.A.; Shokri, J.; Samiel, A.; Kamali-Sarvestani, E.; Barzegar-Jalali, M. and MohmmadiSamani, S. (2011): Nanovaccine for leishmaniasis; preparation of chitosan nanoparticles containing Leishmania superoxide dismutase and evaluation of its immunogenicity in BALB/C mice. Int. J. Nanomed., 6:835-842.

36. Barakat, A.M. (2007): Some diagnostic studies on male New Zealand rabbit experimentally infected with Toxoplasma gondii strain. Glob. Vet., 1(1):17-23.

37. Beutler, E.; Duron, O. and Kelly, B. M. (1963): Improved method for the determination of blood glutathione. J. Lab. Clin. Med., 61:882-8.

38. Ohkawa, H.; Ohishi, W. and Yagi, K. (1979): Assay for lipid peroxides in animal tissues by thiobarbituric acid reaction. Anal. Biochem., 95:351-358.

39. Engvall, E. and Perlmann, P. (1972): Enzyme-linked immunosorbent assay, ELISA. 3. Quantitation of specific antibodies by enzyme-labeled antiimmunoglobulin in antigen-coated tubes. J Immunol., 109(1):129-35.

40. Tripathy, S.; Das, S.; Chakraborty, S.P.; Sahu, S.K.; Pramanik, P.and Roy, S. (2012): Synthesis, characterization of chitosantripolyphosphate conjugated chloroquine nanoparticle and it's in vivo anti-malarial efficacy against rodent parasite: a dose and duration dependent approach. Int. J. Pharmacol., 434 (1-2), 292-305.

41.Esboei, B.; Fakhar, M.; Chabra, A. and Hosseini, M.(2013): In vitro treatments of Echinococcus granulosus with fungal chitosan, as a novel biomolecule. Asian Pacific Journal of Tropical Biomedicine, 3(10):811-5.

42.Schöler, N.; Krause, K.; Kayser, O.; Müller, R.H.; Borner, K.; Hahn, H. and Liesenfeld, O. (2001): Atovaquone nanosuspensions show excellent therapeutic effect in a new murine model of reactivated toxoplasmosis. Antimicrob. Agents Chemother., 45 (6), 1771-1779.

43.Dunay, I.R.; Heimesaat, M.M.; Bushrab, F.N.; Müller, R.H.; Stocker, H.; Arasteh, K.; Kurowski, M. et al ., (2004): Atovaquone maintenance therapy prevents reactivation of toxoplasmic encephalitis in a murine model of reactivated toxoplasmosis. Antimicrob. Agents Chemother., 48 (12), 4848-4854.

44.Shubar, H.M.; Dunay, I.R.; Lachenmaier, S.; Dathe, M.; Bushrab, F.N.; Mauludin, R. et al., (2009): The role of apolipoprotein $\mathrm{E}$ in uptake of atovaquone into the brain in murine acute and reactivated toxoplasmosis. J. Drug Target, 17 (4), 257-267.

45.Grujiè, J.; Djurkovi-Djakovi， O.; Nikolic, A.; Klun, I. and Bobic, B. (2005): Effectiveness of spiramycin in murine models of acute and chronic toxoplasmosis. Int. J. Antimicrob. Agents, 25: 226-230.

46.Sordet, F.; Aumjaudy, Y.; Fessih, H. and Derouin, F. (1998): Assessment of the activity of atovaquone-loaded nanocapsules in treatment of acute and chronic murine toxoplasmosis. Parasite, 5 , 223-229. 
47.Assolini,j;;Concato,V;Gonçalves,M.D. and Carloto,A.C.(2017): Nanomedicine advances in toxoplasmosis: diagnostic, treatment, and vaccine applications. Parasitology Research, 116(8).

48.Tachibana, H.; Yoshihara, E.; Kaneda, Y. and Nakae, T.(1990): Protection of Toxoplasma gondii-Infected Mice by Stearylamine-Bearing Liposomes. Journal of Parasitology, 76(3):352-5.

49.Dunay, I.R.; Heimesaat, M.; Bushrab, F.N.; . Müller, R.H.; Stocker, H. et al., (2004): Atovaquone Maintenance Therapy Prevents Reactivation of Toxoplasmic Encephalitis in a Murine Model of Reactivated Toxoplasmosis. Antimicrob. Agents Chemother., 48(12): 4848-4854.

50.Shubar, H. M.; Lachenmaier, S.; Heimesaat, M. M.; Lohman, U.; Mauludin, R. and Mueller R. H. et al., (2011): SDS-coated atovaquone nanosuspensions show improved therapeutic efficacy against experimental acquired and reactivated toxoplasmosis by improving passage of gastrointestinal and blood-brain barriers. J. Drug Target, 19: 114-124.

51.Schöler, N.; Krause, K.; Kayser, O.; Müller, R.H.; Borner, K.; Hahn, H. and Liesenfeld O. (2001): Atovaquone nanosuspensions show excel-lent therapeutic effect in a new murine model of reactivated toxoplasmosis. Antimicrob. Agents Chemother, 45: 1771-1779.

52.Pissinate; Martins-Duarte, K.S.; Schaffazick, E.; Rezendede Oliveira, S.R. and Padilha, C. et al. (2014):
Pyrimethamine-loaded lipid-core nanocapsules to improve drug efficacy for the treatment of toxoplasmosis. Parasitology research, 0932-0113.

53.Prieto, M.J.; Bacigalupe, D.; Pardini, O.; Amalvy, J.I.; Venturini, C.; Morilla， M.J. and Romero, E.L. (2006): Nanomolar cationic dendrimeric sulfadiazine as potential antitoxoplasmic agent. Int. J. Pharm., 1;326(1-2):160-8.

54. Birben, E.; Sahiner, U.M.; Sackesen, C.; Erzurum, S.; and Omer Kalayci, $O$. (2012): Oxidative stress and antioxidant defense. World Allergy Organ J., 5(1): 919.

55.Guilford, T.(2012): What every doctor should know about glutathione. Vol. 13: (3). Fall, 17:13.

56. El-Badry, A. (2006): Serum malondialdehyde levels as a biomarker of cellular injury in human fascioliasis. J T U Med. Sc., (1): 57-6.

57.Miricescu，D.; Iricescu，Stanescu，I.; Perlea, P.; Erlea, Calenic, B.; Radulescu, R.; Totan, A. and Virgolici, B. (2017): Oxidative stress following PLGA nanoparticles administration to an animal model. Biointerfaces, 75: (1) 1-18.

58.Semete, B.; Booysen, L.; Lemmer,Y.; Kalombo, M.L. and Katata , L. et al., (2010): In vivo evaluation of the biodistribution and safety of PLGA nanoparticles as drug delivery systems. Nanomedicine: nanotechnology, biology, and medicine, 6(5):662-71.

59.Chen, J.; Huang, S.Y.; Zhou, D.H.; Li, Z.Y.; Petersen, E.; Song, H.Q.et al. (2013): DNA immunization with eukaryotic initiation factor-2a of Toxoplasma gondii induces protective 
immunity against acute and chronic toxoplasmosis in mice. Vaccine 31(52):6225-6231.

60. Filisetti, D. and Candolfi, E. (2004): Immune response to Toxoplasma gondii, Annalidell'Istituto Superiore di Sanita, 40: 71-80.

61. Dupont ,C.D.; Christian, D.A. and Hunter, C.A. (2012): Immune response and immunopathology during toxoplasmosis. Semin Immunopathology., 34(6):793-813.

62. Liu, Q.; Chen, X.; Jia, J.; Zhang, W.; Yang, T.; Wang, L. and Ma, G.(2015): pH- Responsive Poly(D,L-lactic-coglycolic acid) Nanoparticles with Rapid Antigen Release Behavior Promote Immune Response. ACS Nano., 26;9(5):4925-38.

63. Hamad, H.; Ramadan, N.; Mohamed, Aly, I.; Zalat, R. (2018): Parasitological and immunological study of the effect of chitosan and chitosan nanoparticles loaded with spiramycin on toxoplasmosis. Journal of Global Pharma Technology, 10(06):138-145.

64. Iqbal, J.; Al-Awadhi, M.A. and Raghupathy, R.G.(2016): TGF- $\beta 1$ levels and intraocular tissue alterations in mice infected with a virulent type I RH Toxoplasma gondii strain. Exp. Parasitol., 162:57-63.

65. Khalil, S.S. and Rashwan, E.A.(1996): Tumour necrosis factor-alpha (TNFalpha) in human toxoplasmosis. J. Egypt Soc. Parasitol., 26(1):53-61.

66. Kulkarni, R.; Deshpande, A.; Saxena, R. and Saxena, K. (2013): A study of serum malondialdehyde and cytokine in tuberculosis patients. JCDR. 7: 21402142 .

67. Koch, B.E.; Stougaard, J. and Spaink, H.P. (2015): Keeping track of the growing number of biological functions of chitin and its interaction partners in biomedical research. Glycobiology, 25:469-482.

68. Xu, Y.; Tang, H.; Liu, J.H.; Wang, H. and Liu, Y.(2013): Evaluation of the adjuvant effect of silver nanoparticles both in vitro and in vivo. Toxicol Lett., 10;219(1):42-8.

69. Couper, K.N.; Alexander, J.; Roberts, C.W.; Johnson, L.L. and Brombacher, F. (2005): Toxoplasma gondii-Specific Immunoglobulin M Limits Parasite Dissemination by Preventing Host Cell Invasion, Infect. Immun., 73:8060-8068.

70. Konishi, E. and Nakao, M. (1992): Naturally occurring immunoglobulin $\mathrm{M}$ antibodies: enhancement of phagocytic and microbicidal activities of human neutrophils against Toxoplasma gondii. J. Parasitol., 104:427-432.

71. Brinkmann, V.; Remington, J.S. and $S$ D Sharma, S.D. (1987): Protective immunity in toxoplasmosis: correlation between antibody response, brain cyst formation, T-cell activation, and survival in normal and B-cell-deficient mice bearing the H-2k haplotype. Infect Immun., 55(4): 990-994. 